\title{
Impact of Acotiamide Affects Meal-related Symptoms and Lower Abdominal Symptoms in Functional Dyspepsia in Japan
}

Hiroshi Yamawaki, Seiji Futagami, Mayumi Shimpuku, Hitomi Sato, Tetsuro Kawagoe, Tomotaka Shindo, Hiroyuki Nagoya, Yasuhiro Kodaka, Choitsu Sakamoto

Department of Gastroenterology, Nippon Medical School, Nippon Medical School, 1-1-5 Sendagi, Bunkyo-ku, Tokyo, 113-8602, Japan

\section{Abstract}

Background: To clarify whether acotiamide improve postprandial distress symptoms and lower abdominal symptoms through affecting hypothalamic-pituitary-adrenal (HPA) axis in FD patients. Methods: We used Rome III criteria to evaluate upper and lower abdominal symptoms. Twenty-five functional dyspepsia (FD) patients were treated with acotiamide $(300 \mathrm{mg} /$ day) for 4 weeks. Anxiety was evaluated using STAI-state/-trait. We measured ACTH and cortisol levels in FD patients.

Results: Acotiamide treatment significantly $(\mathrm{p}=0.007, \mathrm{p}=0.003)$ improved postprandial fullness and early satiety in 4 weeks treatment in FD patients compared to those in pretreatment. In contrast, acotiamide treatment improved lower abdominal symptoms, while insignificantly. Acotiamide did not also affect anxiety using STAI-state/-trait. Acotiamide treatment for 4 weeks did not affect ACTH and cortisol levels in FD patients.

Conclusion: Further studies will be needed to clarify how acotiamide improve clinical symptoms in FD patients.

\section{Introduction}

According to the Rome III criteria, the major symptoms of FD consist of bothersome postprandial fullness, early satiety, epigastralgia, and epigastric burning [1]. The symptom pattern and the underlying pathology of FD are heterogenous. Thus, visceral hypersensitivity in response to distention [2], impaired meal accommodation [3] and delayed gastric emptying has frequently been demonstrated in patients with FD [4-6]. Furthermore, the involvement of several other mechanisms has also been suggested, including duodenal hypersensitivity to the luminal contents, small bowel dysmotility, Helicobacter pylori infection [7], psychological disturbances [8] and central nervous system disorders [9]. Functional dyspepsia is treated by two major categories of drugs; acid inhibitors such as $\mathrm{H} 2$-receptor antagonists and proton pump inhibitors (PPIs), and prokinetic drugs which accelerate disturbed GI motility with modifying altered visceral sensitivity. However, the level of evidence for the efficacy of these approaches is low, and in particular there is a lack of prokinetic drugs of proven value for this condition.

Acotiamide hydrochloride (Z-338), N-[2-(bis(1-methyl-ethyl) amino)ethyl]-2-[(2-hydroxy-4,5-dimethoxybenzoyl)amino]thiazole4-carboxamide monohydrochloride trihydrate, is a first-in-class drug which exerts gastroprokinetic activity by enhancement of acethylcholine release $[1,10]$ via its antagonistic actions on the M1 and M2 muscarinic receptors [11], and partly by inhibiting acetylcholineesterase activity. Matsueda et al. reported that symptom improvement with the optimal dose of acotiamide 100mg t.i.d.was highest for meal-related symptoms, such as postprandial fullness, upper abdominal bloating and early satiation $[12,13]$. In animal models and in man, acotiamide enhances gastric emptying and gastric accommodation, two factors which have been implicated in the pathogenesis of PDS patients $[1,10,11,14]$. However, whether acotiamide alters gastric emptying and accommodation in FD patients is still an unsolved issue. Acotiamide may act directly on the gut and also indirectly through the brain-gut axis via actions in the central nervous system [14]. In this study, we aim to clarify whether acotiamide improve lower gastrointestinal tract symptoms as well as postprandial distress syndrome in FD patients through affecting hypothalamic-pituitary-adrenal (HPA) axis.

\section{Material and Methods}

\section{Patients}

Twenty-five patients presenting with typical symptoms of FD were enrolled after upper gastrointestinal endoscopy and abdominal ultrasonography. Patients were diagnosed according to Rome III criteria [15]. Twenty-five FD patients were treated with acotiamide (300mg/day) for 4 weeks. Exclusion criteria included severe heart disease, renal or pulmonary failure, liver cirrhosis, severe systemic illness and history of malignant disease. Patients with previous gastroduodenal surgery, duodenal ulcer scar, diabetes mellitus, and recent use of NSAIDs, PPIs or anticoagulants at endoscopy were also excluded. H. pylori infection was determined by both the 13C-urea breath test and by histological identification. Written informed consent was obtained from all subjects prior to undergoing upper gastrointestinal endoscopy and abdominal ultra-sonography for evaluation of their dyspeptic symptoms. The study protocol was approved by the Ethics Review Committee of Nippon Medical School Hospital.

\section{Clinical symptoms}

Clinical symptoms of FD were evaluated according to Rome III criteria [15]. Clinical symptoms must have involved at least one of the following: early satiation, bothersome postprandial fullness, epigastric pain, or epigastric burning. Diagnostic criteria for PDS included bothersome postprandial fullness occurring after ordinarysized meals and/or early satiation that prevented completion of a

*Corresponding Author: Dr. Seiji Futagami, MD, PhD, Department of Gastroenterology, Nippon Medical School, Graduate School of Medicine, 1-15 Sendagi, Bunkyo-ku, Japan, Tel: +81-3-3822-2131; Fax: +81-3-5685-1793; E-mail: seiji.futagami@gmail.com

Citation: Yamawaki H, Futagami S, Shimpuku M, Sato H, Kawagoe T, et al. (2014) Impact of Acotiamide Affects Meal-related Symptoms and Lower Abdominal Symptoms in Functional Dyspepsia in Japan. Int J Gastroenterol Disord Ther 1: 109. doi: http://dx.doi.org/10.15344/2393-8498/2014/109

Copyright: (C) 2014 Yamawaki et al. This is an open-access article distributed under the terms of the Creative Commons Attribution License, which permits unrestricted use, distribution, and reproduction in any medium, provided the original author and source are credited. 
Citation: Yamawaki H, Futagami S, Shimpuku M, Sato H, Kawagoe T, et al. (2014) Impact of Acotiamide Affects Meal-related Symptoms and Lower Abdominal Symptoms in Functional Dyspepsia in Japan. Int J Gastroenterol Disord Ther 1: 109. DOI: http://dx.doi.org/10.15344/2393-8498/2014/109

normal meal, with either symptom occurring at least several times a week. Determination of diagnosis for EPS included all of the following: pain or burning that is intermittent localized to the epigastrium, and of at least moderate severity at least once per week. Diagnosis for PDS and EPS was fulfilled with symptoms occurring for the last three months and the onset of symptoms occurring at least six months prior to diagnosis. In this study, we enrolled PDS patients without abdominal pain or epigastric burning. FD symptoms and the feeling of hunger were assessed by visual analogue scale (VAS scale) $[1,16-$ 19]. FD patients was asked to grade the severity (visual analogue scale (VAS): $0-10 ; 0=$ absent, and 10=maximal) of FD symptoms (epigastric pain, epigastric burning, postprandial fullness and early satiety) based on modified previous study [18]. In addition, we assessed abdominal symptoms including constipation and diarrhea using the modified Gastrointestinal symptom Rating Scale (GSRS) [20].

\section{State-Trait anxiety Inventory (STATI)}

The STAI is a well-validated 40-item self-reported questionnaire to evaluate degree of anxiety [21]. The STAI is used to measure both state of anxiety (20 items) and trait of anxiety (20 items), wherein subjects choose one of four levels of anxiety for each item. State of anxiety reflects a "transitory emotional state or condition of the human organism that is characterized by subjective, consciously perceived feelings of tension and apprehension, and heightened autonomic nervous system activity." State of anxiety may fluctuate over time and can vary in intensity. In contrast, trait of anxiety denotes "relatively stable individual differences in anxiety proneness".

\section{Measurement of plasma ACTH and cortisol levels in FD patients}

A cannula was inserted into an anterior forearm vein and the patients were allowed to relax for $30 \mathrm{~min}$. The cannula was kept patent by flushing with heparinized saline. Blood samples were obtained after an overnight fast of $>12 \mathrm{hr}$ and the samples were immediately centrifuged and stored at $-20^{\circ} \mathrm{C}$ until analysis. ACTH was measured using a commercially available two-site immunoradiometric assay. This is a non-extraction assay supplied by the Nichollas Institute, San Juan Capistrano, Calif., USA. The sensitivity of the assay is $5 \mathrm{ng} / \mathrm{ml}$. Intra- and inter-assay coefficients of variation were 3 and $6 \%$, respectively. The reliable lower limit of detection was $4.4 \mathrm{pmol} / \mathrm{l}$ $(10 \mathrm{ng} / \mathrm{l})$. Cortisol was measured by an automated system using an enzyme immunoassay method (Immuno-I, Bayer Diagnostics, Newbury, UK). The sensitivity of the method is $10 \mathrm{nmol} / \mathrm{l}$ and has a between-batch variation of $<5 \%$ over the range $50-1600 \mathrm{nmol} / \mathrm{l}$.

\section{Statistical analysis}

For statistical evaluation of group data, Students't-test for paired data and analysis of variance (ANOVA) for multiple comparisons were followed by Scheffe's F test. Mann-Whitney U test was used for analysis of categorical data. The distribution of alleles at each locus was assessed using the $\chi^{2}$ Statistic of the Hardy-Weinberg equilibrium. To determine factors that associated with the disturbance of gastric emptying, multiple logistic regression analysis was used at $95 \%$ confidence intervals and associated $\mathrm{p}$ values. Data analyses were performed by using standard software package (SPSS version 13.0, Chicago, IL). A P value of less than 0.05 was statistically significant.

\section{Results}

Clinical symptoms in acotiamide-treated FD patients
Acotiamide treatment significantly $(\mathrm{p}=0.007$ and $\mathrm{p}=0.003)$ improved postprandial fullness and early satiety $(3.68 \pm 0.60,3.68 \pm 0.544)$ as PDS symptoms in 4 week treatment compared to those in pretreatment $(5.82 \pm 0.57,5.18 \pm 0.58)$ (Figure 1). In contrast, acotiamide treatment did not $(2.61 \pm 0.27,1.92 \pm 0.98)$ significantly improved constipation and diarrhea score in 4 week treatment in FD patients compared to those in pretreatment $(2.85 \pm 0.27,2.18 \pm 0.248)$ (Figure 2).

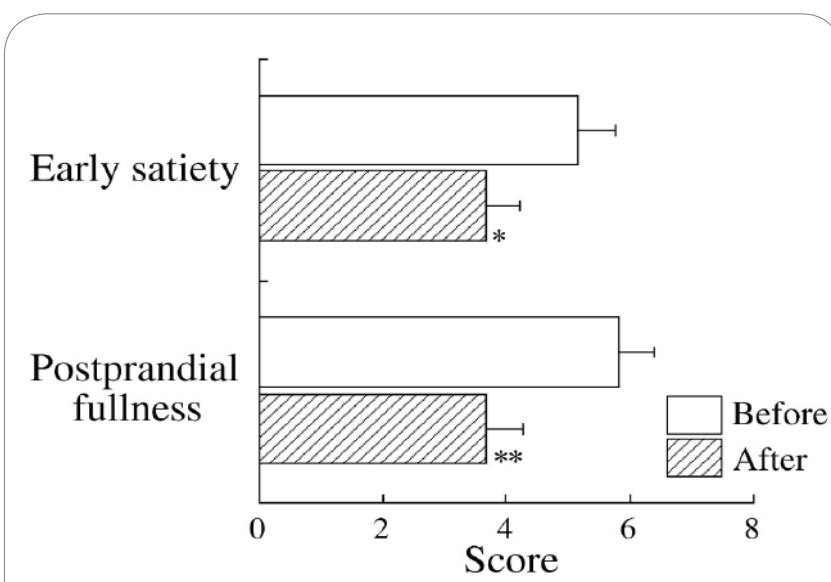

Figure 1: FD symptoms in acotiamide-treated FD patients.

Acotiamide treatment significantly $(\mathrm{p}=0.007$ and $\mathrm{p}=0.003)$ improved postprandial fullness and early satiety in 4 week treatment compared to those in pretreatment.

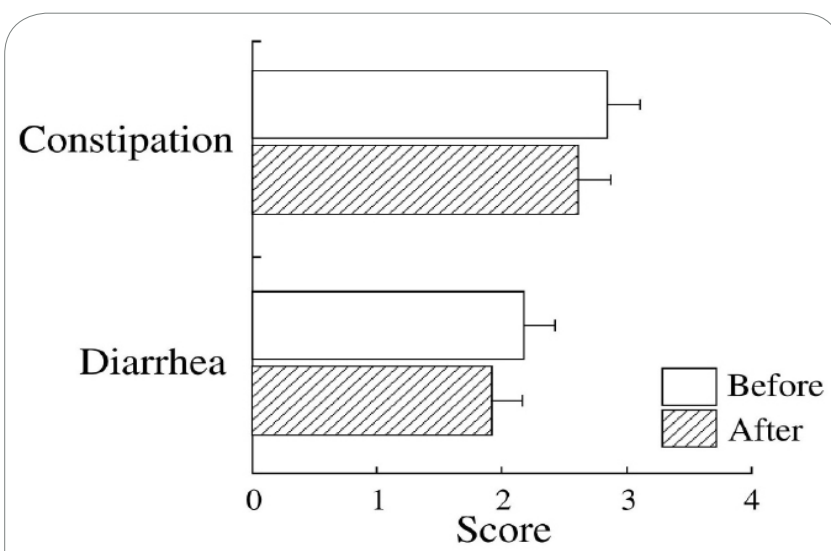

Figure 2: Comparison of lower GI tract symptoms in acotiamidetreated FD patients.

Acotiamide treatment did not $(2.61 \pm 0.27,1.92 \pm 0.98)$ significantly improved constipation and diarrhea score in 4 week treatment in FD patients compared to those in pretreatment $(2.85 \pm 0.27,2.18 \pm 0.248)$.

\section{STAI-state/trait in acotiamide-treated FD patients}

Since acotiamide treatment has been reported to improve FD symptoms, we tried to clarify whether acotiamide affect anxiety in FD patients. In this study, acotiamide treatment did not improved $(47.48 \pm 6.20,46.88 \pm 6.48)$ STAI-state/-trait in 4 week treatment in FD patients compared to those in pretreatment $(47.27 \pm 6.01,48.46 \pm 5.96)$ (Figure 3).

Comparison of the ACTH and cortisol in acotiamide-treated FD patients

To investigate, whether acotiamide improve FD symptom through 
Citation: Yamawaki H, Futagami S, Shimpuku M, Sato H, Kawagoe T, et al. (2014) Impact of Acotiamide Affects Meal-related Symptoms and Lower Abdominal Symptoms in Functional Dyspepsia in Japan. Int J Gastroenterol Disord Ther 1: 109. DOI: http://dx.doi.org/10.15344/2393-8498/2014/109

affecting hypothalamic-pituitary-adrenal (HPA) axis, we measured ACTH and cortisol levels in FD patients. Acotiamide treatment for 4 weeks did not significantly affect ACTH and cortisol levels $(24.64 \pm 2.13 \mathrm{pg} / \mathrm{ml}, 12.37 \pm 0.72 \mu \mathrm{g} / \mathrm{dl})$ in FD patients compared to those in pretreatment $(24.80 \pm 2.64 \mathrm{pg} / \mathrm{ml}, 11.88 \pm 0.87 \mu \mathrm{g} / \mathrm{dl})$ (Figure 4).

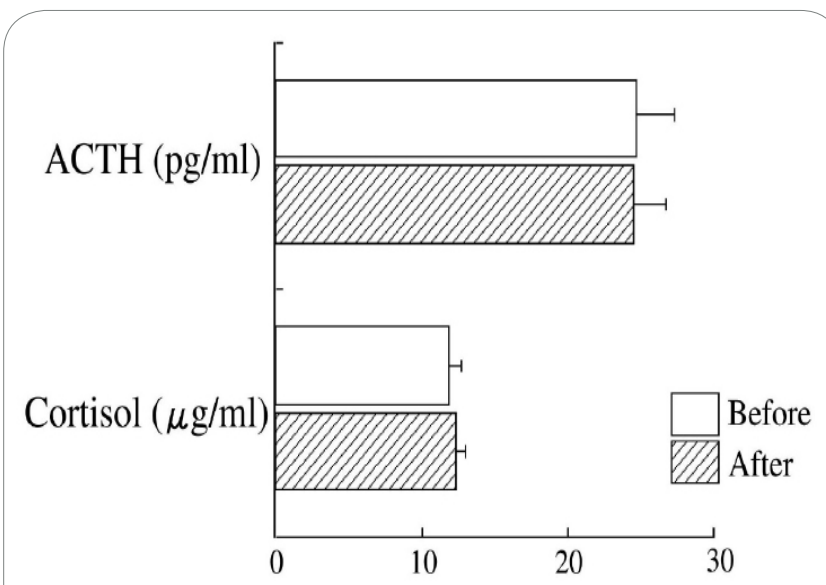

Figure 3: Comparison of STAI-state/trait in acotiamide-treated FD patients.

Acotiamide treatment did not improved STAI-state/-trait in 4 week treatment in FD patients compared to those in pretreatment.

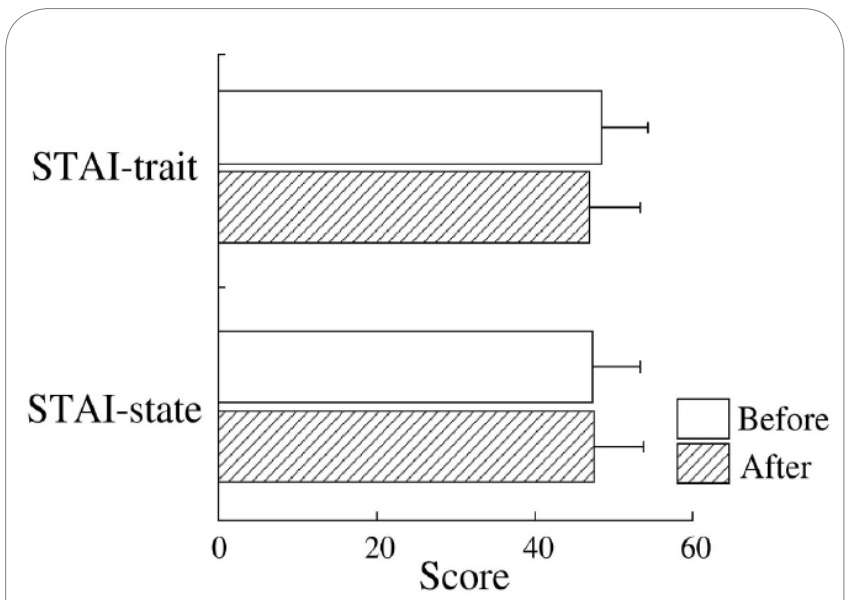

Figure 4: Comparison of the ACTH and cortisol in acotiamidetreated FD patients.

Acotiamide treatment for 4 weeks did not significantly affect ACTH and cortisol levels in FD patients compared to those in pretreatment.

\section{Discussion}

The major findings of this study are: 1) acotiamide treatment significantly improved postprandial fullness and early satiety in 4 weeks treatment, 2) acotiamide treatment for 4 weeks improved constipation score in FD patients, while insignificantly, 3) acotiamide treatment for 4 weeks did not affect ACTH and cortisol levels in FD patients.

In spite of higher prevalence of FD, treatment options for FD are very limited. Systematic reviews of the available literature have indicated that antisecretory drugs and prokinetic agents may be more effective than placebo in relieving FD symptoms [22,23]. Recent study has reported that acotiamide significantly improved PDS symptoms compared to placebo group $[12,13,24,25]$. There is no available data whether acotiamide affect FD symptoms and lower gastrointestinal (GI) tract symptoms. Therefore, in this study, we have first investigated whether acotiamide treatment is more effective for constipation score in FD patients. However, in our data, acotiamide treatment did not significantly improved lower GI tract symptoms. Previous studies have reported that acotiamide enhances acetylcholine release from enteric neurons through muscarinic receptor antagonism and acetylcholineesterase inhibition, thereby enhancing gastric emptying and gastric accommodation [26,27]. Nagahama et al have reported that oral administration of acotiamide stimulated postprandial gastroduodenal and colonic motor activities in conscious dogs [28]. Further studies will be warranted whether acotiamide improve lower GI tract symptoms using measuring lower GI tract motility as well as mosapride citrate reported in our previous study.

\section{Conclusion}

Altered gut-brain interactions may underlie symptom generation in FD patients. Activation of the hypothalamic-pituitary-adernal (HPA) axis followed by secretion of cortisol is considered as a physiological response to stress. HPA axis alterations and stress have been related to gut motor function [29]. However, the interaction between the free cortisol and other relevant variables in FD is scarcely known. Previous study has reported that changes in free cortisol secretion have corresponded to different symptoms of functional gastrointestinal disorders [30]. However, in our data, we could not find any significant differences in cortisol and ACTH levels in acotiamide alone group. Seto et al have also reported that in rat model, acotiamide did not alter adenocorticotropic levels [14]. These results suggest that FD patients did not have enough exposure to daily stress in order to activate the HPA axis and acotiamide treatment did not affect HPA axis in FD patients. Seto et al have reported that acotiamide exerted an impact on the expression of genes related to the expression of neuromedin $\mathrm{U}$, known as a stress-related neuropeptide [14]. Acotiamide may act directly on organs of the gut and, indirectly on CNS via adjustment of the brain gut axis central and peripheral activity $[11,14,31]$. Further studies will be needed to clarify whether acotiamide affect gut hormones such as ghrelin and leptin.

Taken together, acotiamide treatment did not significantly improve lower GI tract symptoms and anxiety. Further studies will be needed to clarify whether long-term administration of acotiamide improve FD symptoms and gut motility.

\section{References}

1. Tack J, Talley NJ, Camilleri M, Holtmann G, Hu P, et al. (2006) Functional gastroduodenal disorders. Gastroenterology 130: 1466-1479.

2. Tack J, Caenepeel P, Fischler B, Piessevaux H, Janssens J (2001) Symptoms associated with hypersensitivity to gastric distention in functional dyspepsia. Gastroenterology 121: 526-535.

3. Tack J, Piessevaux H, Coulie B, Caenepeel P, Janssens J (1998) Role of impaired gastric accommodation to a meal in functional dyspepsia. Gastroenterology 115: 1346-1352.

4. Sarnelli G, Caenepeel P, Geypens B, Janssens J, Tack J (2003) Symptoms associated with impaired gastric emptying of solids and liquids in functional dyspepsia. Am J Gastroenterol 98: 783-788.

5. Stanghellini V, Tosetti C, Paternico A, Barbara G, Morselli-Labate AM, et al (1996) Risk indicators of delayed gastric emptying of solids in patients with functional dyspepsia. Gastroenterology 110: 1036-1042. 
Citation: Yamawaki H, Futagami S, Shimpuku M, Sato H, Kawagoe T, et al. (2014) Impact of Acotiamide Affects Meal-related Symptoms and Lower Abdominal Symptoms in Functional Dyspepsia in Japan. Int J Gastroenterol Disord Ther 1: 109. DOI: http://dx.doi.org/10.15344/2393-8498/2014/109

6. Shindo T, Futagami S, Hiratsuka T, Horie A, Hamamoto T, et al. (2009) Comparison of gastric emptying and plasma ghrelin levels in patients with functional dyspepsia and non-erosive reflux disease. Digestion 79: 65-72.

7. Suzuki H, Masaoka T, Sakai G, Ishii H, Hibi T (2005) Improvement of gastrointestinal quality of life scores in cases of Helicobacter pylori-positive functional dyspepsia after successful eradication therapy. J Gastroenterol Hepatol 20: 1652-1660

8. Yamawaki H, Futagami S, Shimpuku M, Sato H, Wakabayashi T, et al (2014) Impact of sleep disorders, quality of life and gastric emptying in distinct subtypes of functional dyspepsia in Japan. J Neurogastroenterol Motil 20: 104-112.

9. Wilmer A, Van Cutsem E, Andrioli A, Tack J, Coremans G, et al. (1998) Ambulatory gastrojejunal manometry in severe motility-like dyspepsia: lack of correlation between dysmotility, symptoms, and gastric emptying. Gut 42: $235-242$.

10. Tack J, Janssen $P$ (2011) Acotiamide (Z-338, YM443), a new drug for the treatment of functional dyspepsia. Expert Opin Investig Drugs 20: 701-712.

11. Ogishima M, Kaibara M, Ueki S, Kurimoto T, Taniyama K (2000) Z-338 facilitates acetylcholine release from enteric neurons due to blockade of muscarinic autoreceptors in guinea pig stomach. J Pharmacol Exp Ther 294: 33-37.

12. Matsueda K, Hongo M, Tack J, Aoki H, Saito Y, et al. (2010) Clinical trial: dose-dependent therapeutic efficacy of acotiamide hydrochloride (Z-338) in patients with functional dyspepsia $100 \mathrm{mg}$ t.i.d. is an optimal dosage. Neurogastroenterol Motil 22: 618-627.

13. Matsueda K, Hongo M, Tack J, Saito Y, Kato H (2012) A placebo-controlled trial of acotiamide for meal-related symptoms of functional dyspepsia. Gut 61: 821-828.

14. Seto K, Sasaki T, Katsunuma K, Kobayashi N, Tanaka K, et al. (2008) Acotiamide hydrochloride (Z-338), a novel prokinetic agent, restores delayed gastric emptying and feeding inhibition induced by restraint stress in rats. Neurogastroenterol Motil 20: 1051-1059.

15. Drossman DA (2006) The functional gastrointestinal disorders and the Rome III process. Gastroenterology 130: 1377-1390.

16. McColl K1, Murray L, El-Omar E, Dickson A, El-Nujumi A, et al. (1998) Symptomatic benefit from eradicating Helicobacter pylori infection in patients with nonulcer dyspepsia. N Engl J Med 339: 1869-1874.

17. Portincasa P, Altomare DF, Moschetta A, Baldassarre G, Di Ciaula A, et al. (2000) The effect of acute oral erythromycin on gallbladder motility and on upper gastrointestinal symptoms in gastrectomized patients with and without gallstones: A randomized, placebo-controlled ultrasonographic study. Am J Gastroenterol 95: 3444-3451.

18. Chen $\mathrm{CL}$, Lin $\mathrm{HH}$, Chen MC, Huang LC (2005) Dyspeptic symptoms and water load test in patients with functional dyspepsia and reflux disease. Scand J Gastroenterol 40: 28-32.

19. Shimpuku M, Futagami S, Kawagoe T, Nagoya H, Shindo T, et al. (2011) G-protein B3 subunit 825CC genotype is associated with postprandial distress syndrome with impaired gastric emptying and with the feeling of hunger in Japanese. Neurogastroenterol Motil 23: 1073-1080.

20. Svedlund J, Sjödin I, Dotevall G (1988) GSRS--a clinical rating scale for gastrointestinal symptoms in patients with irritable bowel syndrome and peptic ulcer disease. Dig Dis Sci 33: 129-134.

21. Spielberger CD, Goursuch RL, Lushene RE (1983) Manual for the State Trait Anxiety Inventory. Mountain View, CA: Consulting Psychologist Press.

22. Veldhuyzen van Zanten SJ, Jones MJ, Verlinden M, Talley NJ (2001) Efficacy of cisapride and domperidone in functional (nonulcer) dyspepsia: a meta-analysis. Am J Gastroenterol 96: 689-696.

23. Veldhuyzen van Zanten SJ, Cleary C, Talley NJ, Peterson TC, Nyrén O, et al. (1996) Drug treatment of functional dyspepsia: a systematic analysis of trial methodology with recommendations for design of future trials. Am $J$ Gastroenterol 91: 660-673.

24. Kusunoki H, Haruma K, Manabe N, Imamura H, Kamada T, et al. (2012) Therapeutic efficacy of acotiamide in patients with functional dyspepsia based on enhanced postprandial gastric accommodation and emptying: randomized controlled study evaluation by real-time ultrasonography. Neurogastroenterol Motil 24: 540-545, e250-1.
25. Matsueda K, Hongo M, Ushijima S, Akiho H (2011) A long-term study of acotiamide in patients with functional dyspepsia: results from an open-labe phase III trial in Japan on efficacy, safety and pattern of administration. Digestion 84: 261-268.

26. Tack J, Masclee A, Heading R, Berstad A, Piessevaux H, et al. (2009) A dose-ranging, placebo-controlled, pilot trial of Acotiamide in patients with functional dyspepsia. Neurogastroenterol Motil 21: 272-280.

27. Altan E, Masaoka T, Farre R, Tack J (2012) Acotiamide, a novel gastroprokinetic for the treatment of patients with functional dyspepsia: postprandial distress syndrome. Expert Rev Gastroenterol Hepatol 6: 533544.

28. Nagahama K, Matsunaga Y, Kawachi M, Ito K, Tanaka T, et al. (2012) Acotiamide, a new orally active acetylcholinesterase inhibitor, stimulates gastrointestinal motor activity in conscious dogs. Neurogastroenterol Motil 24: 566-574.

29. Taché Y, Bonaz B (2007) Corticotropin-releasing factor receptors and stress-related alterations of gut motor function. See comment in PubMed Commons below J Clin Invest 117: 33-40.

30. Ehlert U, Nater UM, Böhmelt A (2005) High and low unstimulated salivary cortisol levels correspond to different symptoms of functional gastrointestinal disorders. J Psychosom Res 59: 7-10.

31. Nakajima T, Nawata H, Ito $Y$ (2000) Z-338 a newly synthetized carboxyamide derivative, stimulates gastric motility through enhancing the excitatory neurotransmission. J Smooth Muscle Res 36: 69-81. 